DOI: http://dx.doi.org/10.20435/1120

\title{
Gestão da aprendizagem: um enfoque acadêmico e comunitário
}

Learning management: an approach academic and
community

Murillo Araújo Martins ${ }^{1}$

Heitor Romero Marques ${ }^{2}$

${ }^{1}$ Bacharel em Direito. Mestrando em Desenvolvimento Local - UCDB. E-mail: murilloserial12@hotmail.com

${ }^{2}$ Licenciado em Ciências e Pedagogia, Especialista em Filosofia e História da Educação, Mestre em Educação - formação de Professores e Doutor em Desarrollo Local y Planteamiento Territorial. E-mail: heiroma@ucdb.br 


\section{RESUMO ABSTRACT}

Este artigo objetiva observar as condições de chegada do Acadêmico do Curso de Direito da UCDB e a maneira que é gerada a aprendizagem na comunidade universitária. A pesquisa foi de campo, com tendência empírica. A pesquisa foi quantitativa, além da revisão bibliográfica e indutiva. 0 estudo pode ser dito comparativo por correlacionar as representações de acadêmicos de distintos semestres, bem como de docentes. A fundamentação teórica deu-se Skinner,

Piaget, Vygotsky, Ana Mercês Bahia Bock; Odair Furtado, Maria de Lourdes Trassi Teixeira, Le Bourlegat e Ávila. Denota-se que há necessidade de ajustes para que as interações sociais ocorridas na ambiência universitária possam ser enriquecidas com relações primárias. É importante estudar a Gestão da

Aprendizagem no Desenvolvimento Local com enfoque acadêmico e comunitário, porque as divergências de percepção entre docentes e acadêmicos são indicativos da predominância de relações secundárias entre eles.

PALAVRAS-CHAVE gestão da aprendizagem desenvolvimento local enfoque acadêmico
This article lens to note the condinitions about arrival the academic the law course the UCDB and manner the learning process in community academic University. The field was quantitative, Concerning the methodology, the research empirical trend, in which it seeks to apprehend the daily experience of students and teachers different semesters.Regards the data collect of the research is classified as being a quantitative approach, beyond the typing and literature review. The logic question is configured as inductive, because the reasoning adopted will the reality of academic life. Technical base the study can be said comparative. Theorist reaserched was Skinner, Piaget, Vygotsky, Ana Mercês Bahia Bock; Odair Furtado, Maria de Lourdes Trassi Teixeira, Le Bourlegat and Avila.denoted, adjustments are needed to the social interactions that occur within the university ambience can be enriched with primary, fundamental characteristic of a community. is important study the Learning Management in the Local development an Approach Accademic and Community.

\section{KEY WORDS}

learning management local development academic approach 


\section{INTRODUÇÃo}

Demonstra-se, por meio dessa pesquisa, a maneira pela qual acadêmicos e docentes do Curso de Direito da Universidade Católica Dom Bosco (UCDB) geram a aprendizagem no ambiente da comunidade universitária.

O estudo tem por objetivo observar as condições de chegada do Acadêmico, do Curso de Direito da UCDB, levando em conta a maturidade social e intelectual. Igualmente a pesquisa procura evidenciar a organização e gestão dos estudos, dos acadêmicos, além dos ajustes que o docente realiza para desenvolver sua disciplina, em vista da construção da autonomia acadêmica.

Os objetivos específicos propõem analisar a forma pela qual os acadêmicos do curso mencionado estão organizando a sua rotina de estudo.

No que concerne à metodologia, a pesquisa aqui relatada enquadra-se como pesquisa de campo, de tendência empírica, na medida em que procura apreender a vivência do cotidiano de acadêmicos e professores dos terceiros e nonos semestres do curso de Direito da UCDB. Quanto à coleta de dados, a pesquisa classifica-se como sendo de uma abordagem quantitativa, além da tipificação como revisão bibliográfica. Quanto à questão lógica, a pesquisa se configura como indutiva, uma vez que o raciocínio adotado vai da realidade da vida acadêmica para possíveis generalizações. Quanto à base técnica, o estudo pode ser dito comparativo por correlacionar as representações de acadêmicos de distintos semestres ( $3^{\circ}$ e $9^{\circ}$ ), bem como de docentes.

Dentre outras referências bibliográficas, o estudo procura fundamentar-se no pensamento de Jean Piaget, Lev S. Vygotsky e Ana Mercês Bahia Bock; Odair Furtado e Maria de Lourdes Trassi Teixeira. 


\section{A CONSTRUÇÃO DA AUTONOMIA DA APRENDIZAGEM}

A construção da autonomia da aprendizagem se dá de modo lento e gradual ao longo da vida. 0 fenômeno da aprendizagem pode ser entendido empiricamente, como algo tácito ou com base em teorias. A Psicologia e a educação tomaram a aprendizagem como objeto de estudo, na tentativa de analisá-la do ponto de vista do conhecimento científico.

Há inúmeras teorias da aprendizagem, que poderiam ser resumidas em três categorias importantíssimas, quais sejam: a teoria do condicionamento (Skinner) a teoria cognitivista (Piaget) e a sociointeracionista (Vygotsky).

\subsection{0 pensamento de Skinner}

Os manuais de educação indicam que Watson B. F. Skinner (1904-1990) é considerado o mais importante para a linha behaviorista, aplicada à Psicologia da Aprendizagem.

O Behaviorismo de Skinner contribuiu de forma significativa com psicólogos americanos, bem como de outros países onde a Psicologia Americana tem grande influência, como por exemplo, o Brasil. No entendimento de Bock, Furtado e Teixeira (1999, p. 48).

No início dos anos 30, na Universidade de Harvard (Estados Unidos), Skinner começou o estudo do comportamento justamente pelo comportamento respondente, que se tornara a unidade básica de análise, ou seja, o fundamento para a descrição das interações do indivíduo-ambiente.

A linha de estudo desenvolvida por Skinner ficou conhecida por ser radical, termo utilizado pelo próprio autor, em 1945, com o objetivo de designar uma filosofia na área científica para estudar o comportamento, utilizando-se da análise experimental do comportamento.

Segundo a teoria do condicionamento, a aprendizagem é definida pelas consequências do comportamento, enfatizando as 
condições ambientais como forças que a impulsionam. Na concepção de Bock, Furtado e Teixeira (1999, p. 115), a "Aprendizagem é a conexão entre o estímulo e a resposta."

Os teóricos do condicionamento acreditam que se aprende por hábitos, ou seja, há uma relação entre uma resposta e um estímulo, estando de acordo com os elementos que o problema novo tem em comum com outros já estudados, surgindo nova situação, que apresenta semelhança à situação já analisada.

No entendimento de Bock, Furtado e Teixeira (1999), a cognição é o meio pelo qual o mundo dos significados está relacionado à sua origem. A partir do momento em que o ser humano se insere no mundo, existe um laço entre a significação e a realidade em que o indivíduo se encontra.

\subsection{0 pensamento de Jean Piaget}

Jean William Fritz Piaget foi professor de Psicologia na Universidade de Genebra e reconhecido mundialmente pela sua revolução na área da epistemologia. Colaborou de forma fundamental para explicar o desenvolvimento cognitivo, contribuindo com mais de cinquenta livros e centenas de artigos publicados. Para Bock; Furtado e Teixeira (1999, p. 127): "Piaget utilizou, para construção de suas ideias, o modelo biológico". Nessa concepção, Piaget afirma que o ser humano nasce com uma estrutura cognitiva prévia capaz de desenvolver-se e, para tanto, a mente precisa agir sobre o meio. Piaget parte do conceito de que o ser humano se guia pela busca do equilíbrio diante as dificuldades impostas pelo meio.

A teoria piagetiana indica que, a cada situação nova, o sujeito da aprendizagem entra em desequilíbrio e a mente age na busca do equilíbrio, mediante a acomodação, de forma que a cada desiquilibração corresponde uma acomodação e nova equilibração. Disso se pode inferir que a aprendizagem se dá em um processo contínuo da ação mental sobre o meio. 
Para Piaget o processo de aprendizagem se dá por fases, como se seguem:

1 Sensório Motora - ocorre entre 0 a 2 anos de idade, quando a pessoa adquire noção de casualidade, espaço e tempo, interage com o meio demonstrando inteligência prática, há elaboração do conjunto das subestruturas cognitivas que deverão orientar as construções perspectivas e intelectuais posteriores.

2 Pré-Operatória - ocorre entre 2 a 7 anos quando a conduta é egocêntrica, a pessoa vê o mundo a partir de sua perspectiva, sem imaginar outros pontos de vista, ocorre o início do jogo simbólico [faz de conta] com desenvolvimento da linguagem [verbal e não verbal].

3 Operações Concretas - ocorre entre 7 a 12 anos quando há o desenvolvimento da capacidade de pensar de maneira lógica, a pessoa transmite seu próprio pensamento de modo que sua argumentação seja aceita, com diminuição do egocentrismo

4 Operações Lógico-Formais - ocorre a partir de 12 anos de idade e é caracterizada pela capacidade de distinguir entre o real e o possível, já apresenta capacidade de pensar em termos abstratos, de formular hipóteses e testá-las sistemática e independentemente, ocorrendo a construção de mecanismos cognitivos.

Na teoria Piagetiana, há dependência da interação social para a construção e validação da estrutura mental em que cada estágio se desenvolve a partir do que já foi construído anteriormente. A sequência desses períodos é sempre a mesma, variando o ritmo da aquisição de novas habilidades. 0 processo na estruturação pode ser alcançado pelo ensino organizado, mas tem a ver diretamente com as experiências.

A partir dessa análise, há dois termos na teoria Piagetiana que precisam ser entendidos, quais sejam:

1) Organização: trata da capacidade do indivíduo em transformar os elementos assimilados, tornando-os como parte da estrutura do organismo; 
2) Adaptação: relaciona a assimilação e a acomodação de forma indissociável.

Piaget acredita que a criança pode aprender por si mesma sem a interferência de um adulto com o objeto de estudo. Para Piaget, as operações cognitivas no homem estão subordinadas a um processo geral de equilíbrio, que é a tendência do desenvolvimento cognitivo, como um todo.

A teoria cognitivista acredita em um processo de relação do sujeito com o mundo exterior que apresenta consequências no plano da organização interna do conhecimento (conhecida como organização cognitiva). No entendimento de Bock, Furtado e Teixeira (1999), o conteúdo da aprendizagem resulta da organização presente das informações e interações do material com a estrutura cognitiva.

Os autores acima mencionados ressaltam a importância da teoria cognitivista, salientando que ela é o marco inicial para que a pessoa dê significados ao seu papel no contexto social. Para os cognitivistas a aprendizagem se organiza da seguinte maneira:

Aprendizagem mecânica: aborda a aprendizagem de novas fontes apresentando pouca ou nenhuma associação conceitual já existente na estrutura cognitiva.

Aprendizagem significativa: existe quando um novo conceito (ideia ou informações) realiza uma junção com os conceitos relevantes, coesos e presentes na estrutura da linha de pensamento cognitiva.

Para Bock; Furtado e Teixeira (1999, p. 117): “O conhecimento assim adquirido fica arbitrariamente distribuído na estrutura cognitiva, sem se ligar a conceitos específicos". A esse respeito, pode ser considerada, como exemplo, uma pessoa que canta uma música em inglês sem fazer ideia do significado. 


\subsection{0 pensamento de Vygotsky}

Lev Semenovitch Vygotsky foi filólogo e advogado. Depois da Revolução Russa de 1917, atuou na área da Psicologia.

Vygotsky exerce muita influência no universo das pessoas que estudam a questão da aprendizagem, notadamente daquele segmento que considera o contexto social como fator de desenvolvimento humano.

Até a metade do século XIX, a filosofia exercia relevante papel no estudo da natureza do ser humano. Vygotsky analisou três postulações fundamentais para caracterizar os aspectos "típicos do comportamento do ser humano", quais sejam:

1) A relação entre os seres humanos e o seu ambiente físico e social. 2) As formas novas de atividade que fizeram com que o trabalho seja o meio fundamental de relacionamento entre o homem e a natureza e as consequências psicológicas dessas formas de atividade. 3) A natureza das relações entre o uso de instrumentos e o desenvolvendo da linguagem.

Em seus estudos, Vygotsky, ao analisar a inteligência prática, referendou o trabalho de Wolfgang Kohler e as pesquisas de K. Buhler (nas quais estabelecia similaridades entre crianças e macacos antropoides), atribuiu à atividade simbólica uma função organizadora de forma específica que invade o processo de uso de instrumentos e é responsável por novas formas de comportamento. No entendimento de Vygostky (1994, p. 110):

De fato, por acaso é de se duvidar que a criança aprende a falar com os adultos; ou que, através de formulação de perguntas e respostas, a criança adquire várias informações; ou seja, através da imitação dos adultos e através da instrução recebida de como agir, a criança desenvolve um repositório completo de habilidades? De fato, aprendizado e desenvolvimento estão inter-relacionados desde o primeiro dia de vida da criança.

Ao considerar o pensamento Vygostky, pode-se afirmar que a criança aprende desde o dia em que nasce, pois há a presença 
de um adulto fazendo intermediação entre o objeto e a própria criança. Para Bock; Furtado e Teixeira (1999, p. 124):

A aprendizagem da criança inicia-se muito antes de sua entrada na escola, isto porque desde o primeiro dia de vida, ela já está exposta aos elementos da cultura e á presença do outro, que se torna o mediador entre ela e a cultura. A criança vai aprendendo a falar e a gesticular, a nomear objetos, a adquirir informações a respeito do mundo que a rodeia, a manusear objetos da cultura; ela vai se comportando de acordo com as necessidades e as possibilidades. Em todas essas atividades está o "outro".

Fazendo correlações entre o pensamento de Vygostky e de Bock; Furtado e Teixeira, vê-se que a ideia de que o agente externo (no caso o outro) é de extrema importância para a aprendizagem. É por isso que a aprendizagem em Vygostky é dita sociocultural, justamente porque o meio cultural de inserção é determinante no desenvolvimento intelectual.

Na tentativa de unir as ideias de Piaget e Vygostky, Duarte (2000, p. 112) afirma que a teoria de Vigotski não necessita ser complementada pelo construtivismo piagetiano para valorizar o caráter ativo do processo de apropriação, pelo indivíduo. Para ele a visão de Vygostky é o suficiente para explicar a função da mente. Por outro lado há correntes contrárias a teoria explicada.

\section{O PONTO DE VISTA DE PROFESSORES E ACADÊMICOS}

Como dito acima, para se conhecer as representações sociais de professores e acadêmicos, no ambiente da comunidade universitária, quanto à construção da autonomia no processo de aprendizagem, foi realizada uma pesquisa de campo, mediante aplicação de questionário fechado.

O dito questionário, com cinco questões, foi aplicado a dez professores e dez acadêmicos do terceiro e a dez do nono semestre do curso de Direito da Universidade Católica Dom Bosco, cujos resultados estão explicitados na Tabela a seguir. 


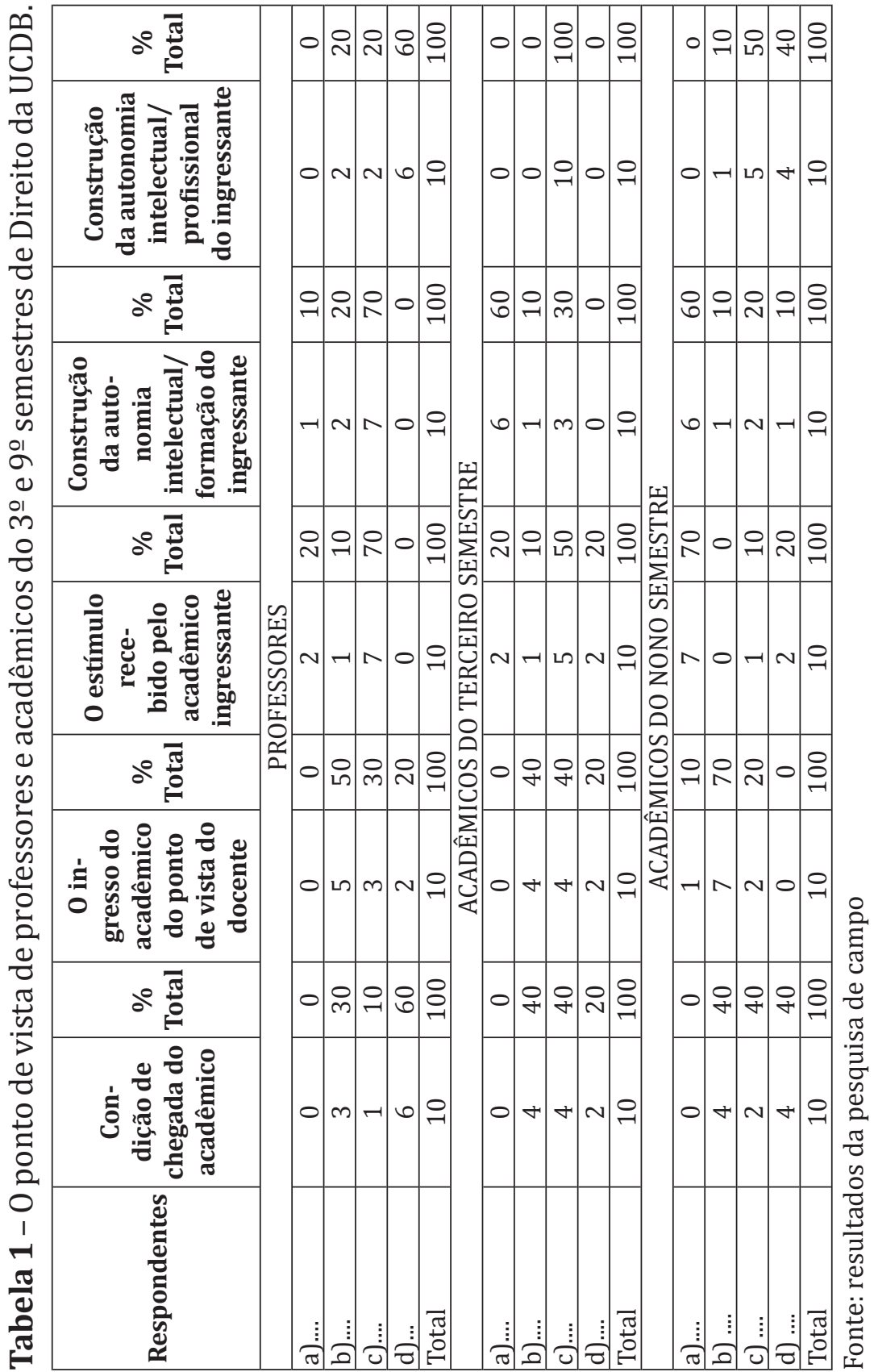




\subsection{Condições de chegada do acadêmico à Universidade}

Para conhecer a condição de chegada do acadêmico foram propostas as seguintes alternativas, a que responderam docentes e acadêmicos do terceiro e nono semestre.

a) Maturidade social e intelectual, com nítida disposição e organização para os estudos.

b) Imaturidade social e intelectual, sem nítida disposição e organização para os estudos.

c) Com relativa maturidade social e intelectual, todavia, com noções de organização e gestão dos próprios estudos.

d) Com relativa maturidade social e intelectual, todavia, sem noções de organização e gestão dos próprios estudos.

Como se pode denotar nos resultados explicitados na Tabela no1 acima, sessenta por cento dos docentes acreditam que o acadêmico do curso de direito da UCDB, ingressa na universidade com relativa maturidade social e intelectual, todavia, sem noções de organização e gestão dos próprios estudos. Isso necessariamente deve implicar postura pedagógica do docente, no sentido de propiciar procedimentos diferenciados para atender a todos os acadêmicos.

Com relação a esses mesmos quesitos, os acadêmicos do terceiro semestre indicaram que quarenta por cento na situação de chegada são de imaturidade social e intelectual, sem nítida disposição e organização para os estudos e outros quarenta por cento assinalaram que a situação de chegada é de relativa maturidade social e intelectual, todavia, com noções de organização e gestão dos próprios estudos. Finalmente outros vinte por cento acreditam que o acadêmico ingressa na universidade com relativa maturidade social e intelectual, todavia, sem noções de organização e gestão dos próprios estudos.

Os acadêmicos do nono semestre se dividem nas percepções: quarenta por cento afirmam que o acadêmico chega à universidade com imaturidade social e intelectual, sem nítida disposição e 
organização para os estudos, e outros quarenta por cento disseram que os acadêmicos chegam com relativa maturidade social e intelectual, todavia, sem noções de organização e gestão dos próprios estudos. Apenas vinte por cento dos acadêmicos do nono semestre afirmaram que os alunos ingressam na universidade com relativa maturidade social e intelectual, todavia, com noções de organização e gestão dos próprios estudos.

Como se pode denotar da primeira questão, não há unanimidade de percepção quanto às condições em que o acadêmico chega à universidade, indicando que o assunto requer atenção por parte dos educadores e dos gestores.

\subsection{0 ingresso do acadêmico do ponto de vista do docente}

Docentes e estudantes do terceiro e novo semestres foram questionados quanto à visão que os docentes têm quanto ao ingresso do acadêmico. Para tanto lhes foram apresentadas as seguintes alternativas:

a) Considera-o maduro em termos sociais e intelectuais e, a partir disso, desenvolve sua disciplina.

b) Considera-o imaturo em termos sociais e intelectuais e, a partir disso, faz ajustes para desenvolver sua disciplina.

c) Considera-o com relativa maturidade social e intelectual e, a partir disso, desenvolve sua disciplina.

d) Considera-o com relativa maturidade social e intelectual e, a partir disso, faz ajustes para desenvolver sua disciplina.

A pesquisa identificou que cinquenta por cento dos professores consideram o acadêmico ingressante imaturo em termos sociais e intelectuais e, a partir disso, fazem ajustes para desenvolver sua disciplina. Outros trinta por cento dos professores consideram o acadêmico ingressante com relativa maturidade social e intelectual e, a partir disso, desenvolvem sua disciplina. Tão somente vinte por cento dos docentes veem o aluno ingressante com relativa maturidade social e intelectual, todavia, sem 
noções de organização e gestão dos próprios estudos.

No tocante aos acadêmicos do terceiro semestre, quarenta por cento deles acreditam que o professor vê o aluno ingressante como imaturo em termos sociais e intelectuais e, a partir disso, faz ajustes para desenvolver sua disciplina, e outros quarenta por cento o considera com relativa maturidade social e intelectual e, a partir disso, desenvolve sua disciplina; apenas vinte por cento o consideram com relativa maturidade social e intelectual e, a partir disso, fazem ajustes para desenvolver sua disciplina.

Os acadêmicos do nono semestre predominantemente, com setenta por cento, acreditam que o docente considera o aluno ingressante imaturo em termos sociais e intelectuais e, a partir disso, faz ajustes para desenvolver sua disciplina. Outros vinte por cento acham que o docente considera o aluno ingressante com relativa maturidade social e intelectual e, a partir disso, desenvolve sua disciplina; apenas dez por cento julgam que o docente considera o aluno ingressante maduro em termos sociais e intelectuais e, a partir disso, desenvolve sua disciplina.

\subsection{0 estímulo recebido pelo acadêmico ingressante}

Seguindo a mesma lógica da pesquisa, docentes e estudantes do terceiro e novo semestres foram questionados quanto ao estímulo recebido pelo acadêmico ingressante. Para tanto lhes foram apresentadas as seguintes alternativas

a) Organiza uma rotina lógica de estudo em função das exigências da sua realidade social.

b) Não organiza uma rotina lógica de estudo em função das exigências da sua realidade social.

c) Conta com o apoio/orientação do corpo docente para organizar uma rotina lógica de estudo.

d) Não conta com o apoio/orientação do corpo docente para organizar uma rotina de estudo. 
Predominantemente, setenta por cento dos docentes responderam que o acadêmico ingressante conta com o apoio/ orientação do corpo docente para organizar uma rotina lógica de estudo, enquanto vinte por cento acham que o aluno ingressante organiza uma rotina lógica de estudo em função das exigências da sua realidade social, e apenas dez por cento defendem que o aluno, ao chegar à academia, não organiza uma rotina lógica de estudo em função das exigências da sua realidade social.

Nessa mesma questão, cinquenta por cento dos acadêmicos do terceiro semestre acreditam que o aluno conta com o apoio/ orientação do corpo docente para organizar uma rotina lógica de estudo. Outros vinte por cento acham que o aluno ingressante organiza uma rotina lógica de estudo em função das exigências da sua realidade social, e outros vinte por cento defendem que o acadêmico ingressante não conta com o apoio/orientação do corpo docente para organizar uma rotina de estudo, e tão somente dez por cento indicaram que os calouros não contam com o apoio/ orientação do corpo docente para organizar uma rotina de estudo.

Coincidentemente com os alunos do terceiro semestre, setenta por cento dos acadêmicos do nono semestre acreditam que o calouro organiza uma rotina lógica de estudo em função das exigências da sua realidade social, enquanto vinte por cento defende que o ingressante não conta com o apoio/orientação do corpo docente para organizar uma rotina de estudo. Tão somente dez por cento indicam que o calouro conta com o apoio/orientação do corpo docente para organizar uma rotina lógica de estudo.

\subsection{A construção da autonomia intelectual e a formação profissional do acadêmico ingressante}

Seguindo a mesma lógica da pesquisa, docentes e acadêmicos responderam à questão sobre a construção da autonomia intelectual e a formação profissional do acadêmico ingressante, 
quando lhes foram propostas as alternativas seguintes:

a) Autogestiona aprendizagem, valendo-se de recursos tecnológicos internos e externos à Universidade.

b) Não autogestiona aprendizagem nem se vale dos recursos tecnológicos internos e externos à Universidade.

c) Delega sua aprendizagem.

d) É indiferente às orientações dos docentes quanto à gestão da aprendizagem.

As respostas dos docentes sobre essa questão resultou que setenta por cento responderam que o acadêmico ingressante delega sua aprendizagem e, com isso, não assume as responsabilidades inerentes ao processo. Outros vinte por cento afiançaram que o calouro não autogestiona a aprendizagem nem se vale dos recursos tecnológicos internos e externos à Universidade. Por último, dez por cento dos docentes acreditam que os alunos ingressantes autogestionan a aprendizagem, valendo-se de recursos tecnológicos internos e externos à Universidade. Paradoxalmente sessenta por cento dos alunos do terceiro semestre acompanham o posicionamento dos dez por cento dos docentes, qual seja, acreditam que o calouro autogestiona a aprendizagem, valendo-se de recursos tecnológicos internos e externos à Universidade. Todavia trinta por cento dos acadêmicos do terceiro semestre se contrapõem à ideia de autogestão por parte dos calouros, indicando que eles delegam a própria aprendizagem, e finalmente dez por cento creem que o aluno ingressante não autogestiona a aprendizagem nem se vale dos recursos tecnológicos internos e externos à Universidade.

Ainda sobre essa questão, sessenta por cento dos acadêmicos do nono semestre defendem que o aluno ingressante autogestiona a aprendizagem, valendo-se de recursos tecnológicos internos e externos à Universidade, enquanto vinte por cento acreditam que eles delegam a própria aprendizagem, outros dez por cento afirmam que o calouro não auto gestiona a aprendizagem nem se 
vale dos recursos tecnológicos internos e externos à Universidade e, por fim, dez por cento assinalam que o calouro é indiferente às orientações dos docentes quanto à gestão da aprendizagem.

\subsection{A construção da autonomia social, intelectual e profissional do acadêmico ingressante}

À última questão versando sobre a construção da autonomia social, intelectual e profissional do acadêmico ingressante, igualmente responderam professores e alunos do terceiro e nono semestres, com a adoção das alternativas abaixo.

a) Segue com rigor as orientações dos docentes quanto à leitura dos textos e documentos indicados pelos docentes.

b) Não segue absolutamente nenhuma orientação dos docentes quanto à leitura dos textos e documentos indicados pelos docentes.

c) Segue parcialmente a orientação dos docentes quanto à leitura dos textos e documentos indicados pelos docentes.

d) Segue parcialmente a orientação dos docentes à leitura dos textos e documentos indicados pelos docentes, mas alega inúmeras dificuldades de operacionalização dos estudos.

As respostas permitem verificar que sessenta por cento dos professores afirmam que o acadêmico de forma geral segue parcialmente a orientação dos docentes à leitura dos textos e documentos indicados pelos docentes, mas alega inúmeras dificuldades de operacionalização dos estudos. Outros vinte por cento acham que o acadêmico não segue absolutamente nenhuma orientação dos docentes quanto à leitura dos textos e documentos indicados pelos docentes e, por fim, outros vinte por cento defendem que o estudante segue parcialmente a orientação dos docentes quanto à leitura dos textos e documentos indicados pelos docentes.

Essa mesma questão quando respondida pelos acadêmicos do terceiro semestre indica que cem por cento deles acreditam que 
seguem parcialmente a orientação dos docentes quanto à leitura dos textos e documentos indicados pelos docentes. Todavia não há unanimidade entre os estudantes do nono semestre visto que cinquenta por cento deles afirmam que o acadêmico de forma geral segue parcialmente a orientação dos docentes quanto à leitura dos textos e documentos indicados pelos docentes, enquanto quarenta por cento defendem que o acadêmico segue parcialmente a orientação dos docentes à leitura dos textos e documentos indicados pelos docentes, mas alega inúmeras dificuldades de operacionalização dos estudos, e apenas dez por cento afiançam que o acadêmico de modo geral não segue absolutamente nenhuma orientação dos docentes quanto à leitura dos textos e documentos indicados pelos docentes.

\section{A COMUNIDADE ACADÊMICA EM VISTA DO DESENVOLVI- MENTO LOCAL}

O ser humano busca, de maneira constante, a dinâmica que há entre o universo em que vive, no sentido de construir e manter sua identidade. Segundo Le Bourlegat (2000), há uma relação entre os fenômenos da mente (considerada ordem interna) do indivíduo com a realidade (denominada ordem externa), e possibilitando a avaliação da consciência do ser humano, na reorganização de novos meios reguladores de manutenção da integridade social.

Nesse sentido, pode-se dizer que estudantes e professores formam uma comunidade acadêmica, na qual dividem a realidade imediata e as perspectivas advindas dessa mesma realidade de inserção.

Como a pesquisa de campo denotou, há necessidade de ajustes para que as interações sociais ocorridas no âmbito da ambiência universitária possam ser enriquecidas com relações primárias, característica fundamental de uma comunidade. As 
divergências de percepção entre docentes e acadêmicos sãos indicativos da predominância de relações secundárias entre eles, aspecto que necessita de ajustes, para que se possa conceber o legítimo desenvolvimento humano, como base do desenvolvimento endógeno.

Faz-se necessário, pois correlacionar os indicativos da pesquisa aqui relatada com a noção de comunidade sugeridas por Phil Barthe (2008), que defende a ideia de que sua formação demanda tempo e não pode ser rotulada. Para ele a comunidade é uma construção mental do tipo sociológica, caracteristicamente formada por um conjunto de interações e comportamentos com significado e expectativa entre seus membros.

A pesquisa indica aspectos fragilizados no tocante às relações estabelecidas no processo de construção da autonomia dos acadêmicos, mediado pelas ações pedagógicas.

Nessa mesma esteira de entendimento, José Carpio Martín citado por Ávila (2000) afirma que a ideia de comunidade resulta em um espaço diversificado que apresenta uma identidade histórica e social, um lugar para conviver e interagir com o objetivo de potenciar o desenvolvimento. Ávila (2000, p. 69) complementa a ideia afirmando que:

[...] a comunidade mesma desabrocha suas capacidades, com-
petências e habilidades de agenciamento e gestão das próprias
condiçõos e qualidade de vida, "metabolizando" comunitaria-
mente as participações efetivamente contributivas de quaisquer
agentes externos.

A partir das concepções acerca daquilo que constitui uma comunidade, é possível afirmar que seus pressupostos podem resultar no que se entende como desenvolvimento local. Quanto mais fortalecida for, por exemplo, a comunidade acadêmica, constituída por professores e alunos, com maior razão se poderia imaginar o desenvolvimento endógeno, por conseguinte local, a partir das ações proativas dos sujeitos que a compõem. 
Nesse sentido, a comunidade acadêmica pode exercer relevante papel no desenvolvimento da localidade de sua inserção, atuando diretamente nas distintas configurações comunitárias.

\section{CONSIDERAÇÕES FINAIS}

\section{0 presente trabalho sobre a gestão da aprendizagem} teve como foco a questão acadêmica e comunitária. Para se conhecer as representações sociais de professores e acadêmicos, no ambiente da comunidade universitária, quanto à construção da autonomia no processo de aprendizagem, foi realizada uma pesquisa de campo, mediante aplicação de questionário fechado.

0 dito questionário, com cinco questões, foi aplicado a dez professores e dez acadêmicos do terceiro e a dez do nono semestre do curso de Direito da Universidade Católica Dom Bosco, partindo-se do pressuposto de que estudantes e professores formam uma comunidade acadêmica, na qual dividem a realidade imediata e as perspectivas advindas dessa mesma realidade de inserção, pelo fato de o ser humano buscar, de maneira constante, a dinâmica que há entre o universo em que vive, originado de seu desejo comum.

Como a pesquisa de campo denotou, há necessidade de ajustes para que as interações sociais ocorridas no âmbito da ambiência universitária possam ser enriquecidas com relações primárias, característica fundamental de uma comunidade. As divergências de percepção entre docentes e acadêmicos são indicativos da predominância de relações secundárias entre eles, aspecto que necessita de fortalecimento, para que se possa conceber o legítimo desenvolvimento humano como base em um possível desenvolvimento endógeno.

A pesquisa indica aspectos fragilizados no tocante às relações estabelecidas no processo de construção da autonomia dos acadêmicos mediado pelas ações pedagógicas. 
A partir das concepções acerca daquilo que constitui uma comunidade, é possível afirmar que seus pressupostos podem resultar no que se entende como desenvolvimento local. Quanto mais fortalecida for, por exemplo, a comunidade acadêmica, constituída por professores e alunos, com maior razão se poderia imaginar o desenvolvimento endógeno, por conseguinte, local, a partir das ações proativas dos sujeitos que a compõem, enquanto protagonistas.

Nesse sentido, a comunidade acadêmica pode exercer relevante papel no desenvolvimento da localidade de sua inserção, atuando diretamente nas distintas configurações comunitárias.

\section{REFERÊNCIAS}

ÁVILA, Vicente Fideles. Pressuposto para formação educacional em desenvolvimento local. Interações - Revista Internacional de Desenvolvimento Local, Campo Grande, MS, v. 1, n. 1, p. 63-76, set. 2000. BATLER, PHIL. 0 que é comunidade? Uma perspectiva sociológica. Tradução de Sofia Ferreira Fernandes, 2008. Disponível em: <https:// cid- 7492046bce02d500.office.live.com/view.aspx/Material\%20 sobre\%20comunidade/COMUNIDADE-PHIL\%20BARTLE.doc $>$. Acesso em: 11 maio 2016.

BOCK, Ana Mercês Bahia; FURTADO, Odair; TEIXEIRA, Maria Lourdes Trassi de. Psicologias uma introdução ao estudo de Psicologia.13. ed. São Paulo: Saraiva, 1999.

LE BOURLEGAT, Cleonice Alexandre. Ordem local como força interna de desenvolvimento . Interações - Revista Internacional de Desenvolvimento Local, Campo Grande, MS, v. 1, n 1, p. 13-20, set. 2000.

DUARTE, Newton. Vigotski e o " aprender a aprender" crítica às apropriações neoliberais e pós-modernas da teoria vigotskiana. Campinas, SP: Autores Associados, 2000.

MARQUES, Heitor Romero et al. Metodologia da pesquisa e do trabalho científico. 4. ed. Campo Grande, MS: UCDB, 2014. 
PIAGET, Jean; GARCIA, Rolando. Psicogênese e história das ciências. Petrópolis: Vozes, 2011.

VYGOTSKY, Lev Semenovich. Pensamento e linguagem. 2. ed. São Paulo: Martins Fontes, 1998.

A formação social da mente. 5. ed. São Paulo: Martins Fontes,1994. 
